\title{
Does Subjective Dietary Knowledge Affect Sugar-Sweetened Carbonated Beverages Consumption and Child Obesity? Empirical Evidence from the Inner Mongolia Autonomous Region in China
}

\author{
Zeqi Liu ${ }^{1}$, Wei Si ${ }^{1,2}$, Qiran Zhao ${ }^{1,2}$ and Chang Tao ${ }^{1, *}$ \\ 1 College of Economics and Management, China Agricultural University, Beijing 100083, China; \\ lzqtx@cau.edu.cn (Z.L.); siwei@cau.edu.cn (W.S.); zhaoqiran@cau.edu.cn (Q.Z.) \\ 2 Academy of Global Food Economics and Policy, China Agricultural University, Beijing 100083, China \\ * Correspondence: B20183110756@cau.edu.cn
}

Citation: Liu, Z.; Si, W.; Zhao, Q.; Tao, C. Does Subjective Dietary Knowledge Affect Sugar-Sweetened Carbonated Beverages Consumption and Child Obesity? Empirical Evidence from the Inner Mongolia Autonomous Region in China. Int. J. Environ. Res. Public Health 2021, 18 , 3713. https://doi.org/10.3390/ ijerph18073713

Academic Editors: Dominika Guzek and Dominika Głąbska

Received: 1 March 2021

Accepted: 29 March 2021

Published: 2 April 2021

Publisher's Note: MDPI stays neutral with regard to jurisdictional claims in published maps and institutional affiliations.

Copyright: (c) 2021 by the authors. Licensee MDPI, Basel, Switzerland. This article is an open access article distributed under the terms and conditions of the Creative Commons Attribution (CC BY) license (https:/ / creativecommons.org/licenses/by/ $4.0 /)$.

\begin{abstract}
Worldwide, overweight and obesity have become an important public health problem affecting the health of children and adolescents. In China, the prevalence of overweight and obesity has reached 19 percent among the 6-17-year-old age group. Although studies have shown that regular consumption of sugar-sweetened beverages (SSBs), especially sugar-sweetened carbonated beverages (SSCBs), is positively correlated with overweight and obesity among children, the research on ways to reduce SSBs consumption is scarce. This study fills this gap by analyzing data on nearly 4000 students aged between 9-15 from the Inner Mongolia Autonomous Region in China, exploring possible influential pathways between subjective dietary knowledge, SSCBs consumption, and child obesity. The estimation results show that SSCBs consumption significantly mediates the relationship between dietary knowledge and the incidence of overweight and obesity; the mediated effects are different among subgroups. Therefore, improving dietary knowledge related to the lowing of SSBs consumption to reduce the obesity risk may be considered a possible way to reduce the prevalence of overweight and obesity among children.
\end{abstract}

Keywords: children; overweight; obesity; sugar-sweetened carbonated beverages; dietary knowledge

\section{Introduction}

Overweight and obesity have become an important public health problem affecting the health of children and adolescents worldwide [1]. These factors are associated with poorer health and wellbeing and higher health-care costs for both the present and future lifetime $[2,3]$.

Between 1975 and 2016, the worldwide prevalence of overweight and obesity among children (5-19 years) more than quadrupled (from 4 percent to 18 percent) [4]; between 2000 and 2016, the prevalence of obesity in children (5-19 years) more than doubled (from 2.9 percent to 6.8 percent) [1]. Although the problem of overweight and obesity was once considered to only exist in high-income countries, it is now increasing in low- and middleincome countries. In the United States, the obesity prevalence among children aged 2-19 increased from 15.4 to 18.5 percent between 2005-2006 and 2015-2016 [5]. In Australia, the prevalence of overweight and obesity among children aged 2-17 has stayed relatively stable around 25 percent since 2007-2008 [6]. In the European World Health Organization member states, from 2007 to 2013, the prevalence of overweight and obesity among children aged 6-9 in more than half of the countries exceeded $25 \%$, among which the prevalence rates in Greece, Italy, and Spain exceeded 40\% [7]. Overweight and obesity among children have shown a concerning upward trend in Asia. It was estimated that in 2019, nearly half of the world's children who were overweight or obese under 5 years of age lived in Asia [4], or 19.1 million. In China, the prevalence of overweight and obesity among 
children and adolescents almost tripled between 2002 and 2020. According to The Chinese National Nutrition and Health Survey In 2002, the prevalence was 6.6 percent for the 7-17 age group [8]; according to the "Report on Nutrition and Chronic Disease Status of Chinese Residents $(2020)^{\prime \prime}$, it has risen to 19 percent for the 6-17 aged group, reaching approximately 34 million (estimated by China Population and Employment Statistics Yearbook-2019 data). Specifically, the obesity rate in the Inner Mongolia Autonomous Region (the surveyed region of the data used in this paper) ranks sixth in the nation, and the overweight rate ranks fourth, with values of $37.6 \%$ and $19.6 \%$, respectively.

The fundamental cause of obesity is an energy imbalance between calories consumed and calories expended [4,9], which is often caused by a complex mixture of dietary [10-13], lifestyle [14,15], genetic [16], psychological [17,18], sociocultural [19,20], economic, and environmental factors $[13,21]$. The intake of energy-dense foods high in sugar is considered one of the main causes of human energy imbalance [4]. According to a series of systematic reviews [22-25], consumption of sugar-sweetened beverages (SSBs), particularly sugarsweetened carbonated beverages (SSCBs), may be a key contributor to the epidemic of overweight and obesity in children and adults. In China, according to the "China Children's Sugary Beverage Consumption Report" released in 2018, the average daily beverage consumption of urban children increased from $329 \mathrm{~mL}$ to $715 \mathrm{~mL}$ between 1998 and 2008 [26]. The 2010-2012 survey on the nutritional and health status of Chinese residents reported that 61.9 percent of children aged 6-17 drank beverages at least once a week. A 2014 national intervention program against obesity in Chinese children and adolescents aged 6-17 years reported that 66.6 percent of participants consumed SSBs and 9.6 percent consumed more than seven servings of SSBs per week [27]. Although there are differences in the methods and results obtained in these studies, they showed that children's intake of free sugar from SSBs exceeded the upper limit recommended by WHO. WHO strongly recommends that the intake of free sugars obtained from food does not exceed $10 \%$ of total energy intake [28].

There is growing evidence that properly designed taxes on SSBs [29-33], especially if the aim is to increase retail prices by $20 \%$ or more [34], and specific interventions that can reduce added sugar intake $[22,24]$ would result in a proportional reduction in SSBs consumption and thus affect the prevalence of overweight and obesity. In China, although studies have shown that regular consumption of sugar-sweetened beverages (SSBs), especially sugar-sweetened carbonated beverages (SSCBs), is positively correlated with overweight and obesity among Chinese children [27,35-37], the research on ways to reduce SSBs consumption to reduce the incidence of overweight and obesity is rare. Since a public opinion support environment for the taxation of sugary beverages has not yet been formed, if a tax on sugary drinks is rashly imposed, it will inevitably arouse public doubts.

To address this gap, this study aims to estimate the possible influence of dietary knowledge, SSCBs consumption, and child obesity in China. Drawing from the idea of "taking preventive measures" in Confucian culture, we determine whether students" dietary knowledge will affect the consumption of SSCBs, thereby affecting the occurrence of overweight and obesity. If an influential pathway exists, it can provide a meaningful reference for the realization of obesity prevention and control goals for Chinese children; it can also promote the awareness of government and citizens with respect to the importance and necessity of a sugar-sweetened beverage tax.

To the best of our knowledge, the present study is the first to explore potential ways to reduce the incidence of overweight and obesity among Chinese children by reducing SSCBs consumption. Existing studies in China mainly focus on the positive correlation between SSCBs consumption and child obesity [27,35-37], but they have not continued to explore solutions in depth. To investigate the possible influential pathways, a field survey was designed to assess all sample students' health status, subjective dietary knowledge, and consumption of SSCBs, and a simultaneous equation system was specified to perform mediation analysis by using three-stage least squares. This study aims to draw a general profile of the prevalence of overweight and obesity among children in the surveyed region 
and assess the possible ways to reduce this endemic prevalence. Through the analysis, it is also hoped that more targeted and cost-effective suggestions can be put forward to prevent further increases in the prevalence of overweight and obesity in Chinese children.

\section{Materials and Methods}

\subsection{Materials}

\subsubsection{Survey Design}

The study consisted of a regionally representative sample of Inner Mongolia Autonomous Region children attending the fourth and fifth grades in elementary schools and of the seventh and eighth grades in junior high schools during the academic year 2019/2020. According to the Monitoring Data on Chronic Diseases and Risk Factors (2017) released by the Chinese Center for Disease Control and Prevention (CCDCP), the overweight and obesity rates in the Inner Mongolia Autonomous Region are higher than the national average. In the "Implementation Plan for Child and Adolescent Obesity Prevention and Control" formulated by the National Health Commission, the Ministry of Education, and four other departments of the People's Republic of China, released in October 2020, this region was classified as a high-endemic area of overweight and obesity among children and adolescents in China [38]. The survey involved the following data collection modules:

- All students selected as survey subjects participated in physical measurements (i.e., height and weight) in their classrooms. Then, each completed a questionnaire, including personal characteristics (such as gender, age, hukou, sibling number, etc.), dietary knowledge items related to their cognition, and practical consumption of common snacks with a high sugar content.

- The caregiver of every student completed a questionnaire on parental information and the family socioeconomic status, such as parental age, education level, height and weight, and durable household assets, etc.

\subsubsection{Study Population}

This study used a cross-sectional dataset collected in 2019, covering a respective sample of 36 compulsory schools, including 4105 children and their respective parents. Overall, the current analysis included:

- 36 schools from the Jining District, Ulanqab city (all compulsory education schools in this district), including 25 primary schools and 11 junior high schools.

- A randomly selected sample of 4105 students with valid data on physical measurements and semi-structured questionnaires, including 52.1 percent who were girls (Table 1). Among the entire sample, about 62.3 percent were primary school students, and 51.6 percent have rural hukou. [156 of sampled children (3.8 percent) did not complete the questionnaire for various reasons].

- 3949 family questionnaires (96.9 percent were completed by sampled parents, and the rest were completed by other relatives of the children).

Table 1. Sample distribution according to selected personal characteristics.

\begin{tabular}{cccccccccc}
\hline \multirow{2}{*}{ Characteristic ${ }^{*}$} & \multirow{2}{*}{ Total } & \multicolumn{2}{c}{ Gender } & \multicolumn{2}{c}{ Hukou } & \multicolumn{3}{c}{ Grade } \\
\cline { 3 - 10 } & & Boys & Girls & Urban & Rural & 4th & 5th & 7th & 8th \\
\hline Frequency & 3949 & 1892 & 2057 & 1733 & 1622 & 1655 & 804 & 1044 & 446 \\
Percentage & $100.0 \%$ & $47.9 \%$ & $52.1 \%$ & $51.6 \%$ & $48.4 \%$ & $41.9 \%$ & $20.4 \%$ & $26.4 \%$ & $11.3 \%$ \\
\hline
\end{tabular}

${ }^{1}$ China's hukou system is the household registration system used in Mainland China. Every citizen is classified as an agricultural or non-agricultural household registration (usually called a rural hukou or an urban hukou) and is further classified by place of birth. Source: Author's survey. 


\subsubsection{Sampling}

The samples were collected by a multi-stage, stratified, random sampling procedure. In China, compulsory education is a nine-year education period and is divided into two stages. The first stage is the six-year elementary education. The second stage is the threeyear junior high school education. Elementary schools and junior high schools in the surveyed region are separate, rather than nine-year uniform education schools. Since the project team plans to conduct a 3-year follow-up survey in this region of China, more classes were selected in the lower grades of each education stage to ensure that a large proportion of samples can be followed up. The specific steps were as follows:

- First, the project team obtained a list of compulsory schools (whether public or private schools) from Jining District's bureau of education. Based on this, four project team numbers phoned the principal of each school to confirm the schedule, and 36 of the 37 compulsory education schools in the district participated in this survey.

- Then, the project team randomly chose two Grade 4 classes and one Grade 5 class in each primary school and randomly chose two Grade 7 classes and one Grade 8 class in each junior high school. A total of 104 classes (three of the schools had only one Grade 4 class that was the only choice; one of the schools did not have a Grade 5 class) were chosen.

- All students in selected classes were the research objects of the survey.

\subsubsection{Data Collection}

To implement data collection, the project team prepared some necessary materials, such as investigator handbooks, portable scales, tape measures, student questionnaires, and family questionnaires. The questionnaires were developed based on similar surveys; for instance, China Health and Nutrition Survey, China Family Panel Studies, and previous surveys of this project team [13]. The project team evaluated the validity of the questionnaire through a small-scale pre-survey method and modified certain contents of the questionnaire based on the results of the survey, such as the type of sugar-sweetened beverages and the type of household fixed assets involved.

The present study was approved by the Ethics Committee of China Agricultural University. All procedures involving human participants followed the 1964 Declaration of Helsinki and its subsequent amendments. Before the fieldwork, all necessary permission from the local government, local education bureaus, and the sampled schools to conduct the survey was obtained. All students and their respective caregivers participating in this survey had full knowledge of the survey purpose and agreed with participation.

Physical measurements, including height and weight, were performed on every student by using a portable scale and tape measure. Then, each student filled out the modules of dietary knowledge items related to their cognition and the modules of practical consumption of SSBs in the questionnaire with the assistance of trained enumerators and teachers. After that, the children continued to complete other modules in the questionnaire in the classroom. The family questionnaire, involving family socioeconomic information, was taken home by the children and filled out by their respective caregiver, and then collected by the headteacher and given to us.

Of all 4105 students in the sample, 3949 completed the survey completely, involving all aspects and questionnaire information, including body measurement, dietary knowledge, carbonated beverage consumption table, and basic information of individuals and families. The information of these students constituted the database of statistical analysis and regression analysis, that is, the final sample included 3949 students.

\subsection{Outcomes of Interests}

\subsubsection{Body Mass Index-for-Age Z-Score, Overweight, and Obesity}

In the physical measurement stage, the height (unit: $\mathrm{m}$ ) and weight (unit: $\mathrm{kg}$ ) of the students were measured. Then, their body mass index-for-age z-score (i.e., BMI-forage $\mathrm{z}$-score) was calculated by WHO AnthroPlus and used to assess students' overall 
health status [39]. BMI-for-age z-score is a suitable growth reference for the 5-19-year age group and is recommended by the WHO for both clinical and epidemiological use [40,41]. The factors of sex and age are fully considered in the calculation process of the BMI-for-age $\mathrm{z}$-score, irrespective of ethnicity [39]. The cut-off points for defining overweight and obesity are taken as +1 standard deviation(sd) and $+2 \mathrm{sd}$, coinciding with adult BMI at $25 \mathrm{~kg} / \mathrm{m}^{2}$ and $30 \mathrm{~kg} / \mathrm{m}^{2}$, respectively. Noting that, in this study, cut-off points for defining overweight are taken as BMI-for-age $z$-score $>+1$ sd, including BMI-for-age $z$-score $>+2$ sd, instead of the usual BMI-for-age $z$-score $>+1$ sd but $<+2$ sd; the cut-off point for defining obesity is taken as BMI-for-age $z$-score $>+2$ sd. (Tables 2 and 3 ).

Table 2. Statistics of dependent variables, independent variables, and control variables.

\begin{tabular}{|c|c|c|c|c|}
\hline Variable $^{1}$ & Definition & Obs. & Mean & Standard Deviation \\
\hline \multicolumn{5}{|c|}{ Outcomes } \\
\hline BMI-for-age z-score & Body mass index-for-age $\mathrm{z}$-score & 3949 & 0.33 & 1.33 \\
\hline Overweight & $\begin{array}{l}\text { Dummy: }=1 \text { if yes }(z-\text { score }>+1 \text { sd }) \\
=0 \text { if normal }(z-\text { score } \geq-2 \text { sd, and } z-\text { score } \leq+1 \text { sd })\end{array}$ & 3840 & 0.32 & 0.47 \\
\hline Obesity & $\begin{array}{l}\text { Dummy: }=1 \text { if yes }(z-\text { score }>+2 \text { sd }) \\
=0 \text { if normal }(z-\text { score } \geq-2 \text { sd, and } z \text {-score } \leq+1 \text { sd })\end{array}$ & 3130 & 0.16 & 0.37 \\
\hline \multicolumn{5}{|c|}{ Dietary Knowledge/SSCBs Consumption } \\
\hline Dietary knowledge & Subjective dietary knowledge of student & 3949 & 20.71 & 3.48 \\
\hline SSCBs_mL & Consumption of SSCBs per day (units: $\mathrm{mL} / \mathrm{d}$ ) & 3949 & 38.09 & 46.08 \\
\hline SSCBs_freq & Consumption frequency of SSCBs per week (units: drink/w) & 3949 & 1.34 & 1.55 \\
\hline \multicolumn{5}{|c|}{ Personal/Family Characteristics } \\
\hline Boy & Dummy: $=1$ if the student is a boy & 3949 & 0.48 & 0.50 \\
\hline Agemonth & Age measured by month & 3949 & 140.98 & 18.79 \\
\hline Preschool & Dummy: $=1$ if the student had received pre-school education & 3949 & 0.98 & 0.15 \\
\hline Sibling number & The number of siblings & 3949 & 0.81 & 0.73 \\
\hline Age_father & Age of father & 3949 & 41.31 & 5.65 \\
\hline Age_mother & Age of mother & 3949 & 39.09 & 5.37 \\
\hline Edu_father & Educational years of father & 3949 & 3.54 & 1.18 \\
\hline Edu_mother & Educational years of mother & 3949 & 3.39 & 1.27 \\
\hline BMI_father & Body mass index of father & 3949 & 24.18 & 3.41 \\
\hline BMI_mother & Body mass index of mother & 3949 & 23.06 & 3.13 \\
\hline Household assets & The household durable asset index & 3949 & -0.13 & 0.79 \\
\hline
\end{tabular}

${ }^{1}$ Source: Authors' survey.

\subsubsection{Dietary Knowledge}

Dietary knowledge (DK) in this study is the degree of students' subjective identification of a series of statements describing dietary knowledge. It is measured using a partial version of the Diet Knowledge Table (DKT) from China Health and Nutrition Survey 2011-Child Questionnaires [42]. The China Health and Nutrition Survey (CHNS), an ongoing open cohort, international collaborative project between the Carolina Population Center at the University of North Carolina at Chapel Hill and the National Institute for Nutrition and Health (NINH, former National Institute of Nutrition and Food Safety) at the Chinese Center for Disease Control and Prevention (CCDC), is a representative survey project that has lasted more than 30 years in China. The DKT consists of 12 items describing dietary knowledge. This survey had four items that are suitable for the cognitive ability of the sample group in this study, such as

- "Choosing a diet with a lot of fresh fruits and vegetables is good for one's health",

- "Eating a lot of sugar is good for one's health",

- "Consuming milk and dairy products is good for one's health",

- "The heavier one's body is, the healthier he or she is". 
Table 3. BMI-for-age z-score distribution of students by personal/family characteristics in full sample and subgroups.

\begin{tabular}{|c|c|c|c|c|c|c|c|c|c|c|c|c|c|c|c|}
\hline \multirow{4}{*}{ Variable $^{1}$} & \multirow{4}{*}{\begin{tabular}{|l} 
All \\
(1)
\end{tabular}} & \multicolumn{9}{|c|}{ Subgroup } & & & & & \\
\hline & & \multicolumn{2}{|c|}{ Gender } & \multicolumn{2}{|c|}{ School Type } & \multicolumn{2}{|c|}{ Only Child } & \multicolumn{3}{|c|}{ BMI of Parent } & \multicolumn{5}{|c|}{ Mean Difference } \\
\hline & & Boys & Girls & $\begin{array}{c}\text { Primary } \\
\text { School }\end{array}$ & $\begin{array}{c}\text { Junior High } \\
\text { School }\end{array}$ & Yes & No & $\begin{array}{c}\text { Both } \\
\text { Normal }\end{array}$ & $\begin{array}{c}\text { Either } \\
\geq 25\end{array}$ & $\begin{array}{c}\text { Either } \\
\geq 30\end{array}$ & & & & & \\
\hline & & (2) & (3) & (4) & (5) & (6) & (7) & (8) & (9) & (10) & (2)-(3) & (4)-(5) & $(6)-(7)$ & (8)-(9) & (8)-(10) \\
\hline $\begin{array}{l}\text { BMI-for-age } \\
\text { z-score }\end{array}$ & 0.33 & 0.51 & 0.15 & 0.34 & 0.31 & 0.40 & 0.29 & 0.13 & 0.54 & 0.72 & $0.36^{* * *}$ & 0.03 & $0.11^{* *}$ & $-0.41^{* * *}$ & $-0.60^{* * *}$ \\
\hline Overweight & 0.32 & 0.40 & 0.24 & 0.33 & 0.29 & 0.34 & 0.30 & 0.26 & 0.38 & 0.44 & $0.16^{* * *}$ & $0.04^{* *}$ & $0.04^{* *}$ & $-0.12^{* * *}$ & $-0.18^{* * *}$ \\
\hline Obesity & 0.16 & 0.25 & 0.09 & 0.18 & 0.14 & 0.19 & 0.15 & 0.11 & 0.22 & 0.28 & $0.16^{* * *}$ & $0.04^{* * *}$ & $0.04^{* * *}$ & $-0.11^{* * *}$ & $-0.17^{* * *}$ \\
\hline
\end{tabular}


Since children may have difficulty understanding the six items that involve phrases such as "Choosing a diet high in fat is good for one's health" and "Reducing the amount of fatty meat and animal fat in the diet is good for one's health", this article uses

- "The development of good eating habits is very beneficial to health"

As a representative. (Appendix A. Table A1)

The respondents were asked if he or she strongly agrees, somewhat agrees, neutral, somewhat disagrees, or strongly disagrees with each statement. The students were reminded that the question is not asking about their actual habits. The options were scored as strongly disagree $=1$, disagree $=2$, neutral $=3$, agree $=4$, strongly agree $=5$, or unknown $=0$. In the present study, DK is scored in the traditional method, in which the score for each statement is summed to a single total measure (Table 2).

\subsubsection{Sugar Intake from Sugar-Sweetened Carbonated Beverages (SSCBs)}

Two indicators are used to measure sugar intake in sugar-sweetened carbonated beverages (SSCBs). Considering the limitations of the data research process, that is, the survey method used was to guide students to review the consumption and frequency of SSCBs in the past week, the recall data might be a rough estimate of the actual intake with relatively low accuracy. Therefore, two indicators are used for help in estimation and mutual verification. Before the formal investigation, a pilot survey was conducted. In particular, a forum with the school administrative staff and parent representatives was held to find out the possible choices of students, which helped to ensure the quality of the recovery data. During the investigation, the targeted students recorded their recall of SSBs consumption with possible help from trained investigators to ensure the quality of the recall data.

The first indicator is the consumption of sugar-sweetened carbonated beverages per day (units: milliliter per day; SSCBs_mL). Information about SSCBs consumption was obtained from the modules of practical consumption of SSBs. For every SSBs in the table, the number of milliliters per serving was defined, and one serving of SSCBs was defined as $350 \mathrm{~mL}$. Students were asked how many servings they had consumed during the previous week. To facilitate students to understand the type and the capacity unit of SSCBs, the investigator provided images of SSCBs and provided unlabeled beverage bottles of different sizes as a reference during the investigation. Four levels were fixed for SSCBs consumption: (i) never or rarely per week, (ii) 1 serving per week, (iii) 2-3 servings per week, and (iv) at least 4 servings per week (noting the quantity). Then the indicator, SSCBs_mL, was calculated based on the number of SSCBs servings consumed by students per week and the quantity per serving. (Table 2)

To further provide complementary information on students' SSCBs consumption, the present paper resorts to the second indicator, namely, the consumption frequency of sugar-sweetened carbonated beverages (SSCBs_freq). Information about SSCBs_freq was also obtained from the modules of the practical consumption of SSBs, by asking each student how frequently they had drunk SSCBs throughout the previous week. Four levels were fixed for SSCBs consumption frequency: (i) never or rarely per week, (ii) 1 or 2 times per week, (iii) 3 to 5 times per week, and (iv) at least 7 times per week (noting the quantity) (Table 2).

\subsubsection{Control Variables}

Based on the semi-structured questionnaires that student and their caregivers independently completed about their personal information and family socioeconomic status, a series of control variables (i.e., personal and family characteristics presented in Table 2) [43-46] were generated.

\subsection{Estimation Method}

Drawing from the idea of "taking preventive measures" in Confucian culture, the major objective of this study is to analyze the possible influential pathway of subjective dietary knowledge, SSCBs consumption, and child overweight and obesity, that is, the subjective 
dietary knowledge affects the incidence of overweight and obesity among students through SSCBs consumption. To meet the study's objectives, a hypothetical mediational model is devised as shown in Figure 1, predicated on the following hypotheses:

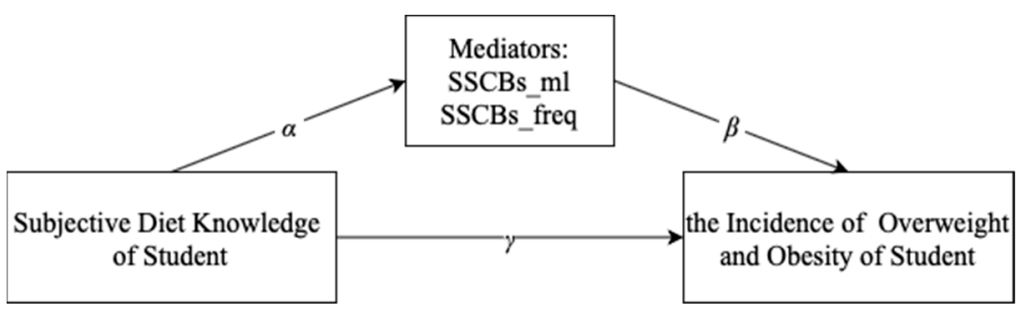

Figure 1. A hypothetical mediational model: Subjective dietary knowledge affects the incidence of overweight and obesity among students through SSCBs consumption.

Hypothesis 1. Subjective dietary knowledge will be related negatively to the consumption of sugar-sweetened carbonated beverages per day (SSCBs_mL). $\left(\alpha_{1}<0\right)$

Hypothesis 2. Subjective dietary knowledge will be related negatively to the consumption frequency of sugar-sweetened carbonated beverages per week (SSCBs_freq). $\left(\alpha_{2}<0\right)$

Hypothesis 3. SSCBs_mL will be related positively to the prevalence of overweight and obesity. $\left(\beta_{1}>0\right)$

Hypothesis 4. SSCBs freq will be related positively to the prevalence of overweight and obesity. $\left(\beta_{2}>0\right)$

The simultaneous equation systems are specified as follows:

$$
\begin{gathered}
\left\{\begin{array}{c}
\text { SSCBS_ml }_{i}=c+\alpha_{1} \cdot D K_{S I_{i}}+\Delta \cdot \text { Controls }_{i}+\mu_{j i} \\
\text { Outcomes }_{j i}=c+\beta_{1} \cdot S S C B s_{-} m l_{i}+\gamma \cdot D K_{i}+\Delta \cdot \text { Controls }_{i}+\varepsilon_{j i}
\end{array}\right. \\
\left\{\begin{array}{c}
\text { SSCBs_freq }_{i}=c+\alpha_{2} \cdot D K_{S I_{i}}+\Delta \cdot \text { Controls }_{i}+v_{j i} \\
\text { Outcomes }_{j i}=c+\beta_{2} \cdot S S C B s_{-} \text {freq }_{i}+\gamma \cdot D K_{i}+\Delta \cdot \text { Controls }_{i}+\varepsilon_{j i}
\end{array}\right.
\end{gathered}
$$

where the outcome variable, Outcomes $j i$, is the $i$ th student's health status (i.e., BMI-forage $\mathrm{z}$-score, overweight, and obesity). $S S C B s_{-} m l_{i}$ is the consumption of sugar-sweetened carbonated beverages per day of the $i$ th student. $S S C B s_{-}$freq $q_{i}$ is the consumption frequency of sugar-sweetened carbonated beverages per week of the $i$ th student. The term $\alpha$ measures the correlation between subjective dietary knowledge and SSCBs consumption indicators; $\beta$ measures the correlation between SSCBs consumption indicators and student's health outcomes. The terms $\alpha$ and $\beta$ are the coefficients of interest and will be used to calculate the indirect effects of the DK on students' health status. The term $\gamma$ measures the correlation between subjective dietary knowledge and student's health outcomes, that is, the direct effect of DK on student's health outcomes. The vector $X_{i}$ is comprised of a set of control variables (mentioned in Section 2.2.3), and $\Delta$ is the related coefficient vector. The term $\mathrm{c}$ is the intercept, and $\varepsilon$ and $v$ represent random errors that exist in a normal distribution. Here, $i$ represents each of the observations. To gain a deeper understanding, the present paper analyzed heterogeneity among subgroups grouped according to personal or family characteristics, since these characteristics appeared to be effect modifiers or moderators.

The mediation analysis is performed using three-stage least squares (3SLS). For a multi-equation system, if the equation contains endogenous explanatory variables, the two-stage least squares (2SLS) estimation for each equation is consistent, but it is not the most efficient, as the single equation 2SLS ignores the possible existence of disturbance terms in different equations correlation. Since DK may be an endogenous explanatory variable affected by the control variables of individual and family characteristics, three- 
stage least squares (3SLS) [47] which is more efficient in this situation, are obtained to simultaneously estimate the simultaneous equation system. The three-stage least squares method of estimating a structural equation consists of three steps, the first of which serves to separate the exogenous part of the endogenous variable, the second to use the exogenous part for regression, and the third to obtain the estimation of the covariance matrix of the disturbance term of the entire system. Then, on this basis, generalized least squares estimation (similar to the seemingly unrelated regression estimation method [48]) is performed on the entire system.

Firstly, models of BMI-for-age z-score are analyzed starting with a model with SSCBs_mL as a mediator, followed by a model with SSCBs_freq as a mediator. All models exhibited a good fit for the data. The process is repeated for overweight, and then for obesity; both models exhibited good fits for the data, as shown in Tables 4 and 5.

Table 4. Mediation analysis based on standardized regression weights from simultaneous equation modeling with SSCBs_mL as a mediator (for the entire sample).

\begin{tabular}{|c|c|c|c|c|c|c|}
\hline \multirow[b]{2}{*}{ Variables $^{1}$} & \multicolumn{2}{|c|}{1.} & \multicolumn{2}{|c|}{2.} & \multicolumn{2}{|r|}{3.} \\
\hline & SSCBs_mL & $\begin{array}{l}\text { BMI-for-Age } \\
\text { z-Score }\end{array}$ & SSCBs_mL & $\begin{array}{c}\text { Overweight } \\
\text { (=1 if Yes) }\end{array}$ & SSCBs_mL & Obesity (=1 if Yes) \\
\hline DK & $\begin{array}{c}-0.776^{* * *} \\
(0.210)\end{array}$ & $\begin{array}{l}-0.003 \\
(0.006)\end{array}$ & $\begin{array}{c}-0.806^{* * *} \\
(0.213)\end{array}$ & $\begin{array}{c}0.001 \\
(0.002)\end{array}$ & $\begin{array}{c}-0.542 * * \\
(0.232)\end{array}$ & $\begin{array}{c}0.001 \\
(0.002)\end{array}$ \\
\hline SSCBs_mL & - & $\begin{array}{c}0.002 \\
(0.003)\end{array}$ & - & $\begin{array}{l}0.002 * * \\
(0.001)\end{array}$ & - & $\begin{array}{c}0.004^{* * *} \\
(0.001)\end{array}$ \\
\hline Control variables & Yes & Yes & Yes & Yes & Yes & Yes \\
\hline Observations & 3949 & 3949 & 3840 & 3840 & 3130 & 3130 \\
\hline R-squared/Chi2 & $0.03 / 102.6$ & $0.06 / 290.2$ & $0.03 / 101.8$ & $0.02 / 279.6$ & $0.03 / 83.8$ & $-0.14 / 278.1$ \\
\hline Mediated effect $\left(\alpha^{*} \beta\right)$ & \multicolumn{2}{|c|}{$\begin{array}{l}-0.002 \\
(0.002)\end{array}$} & \multicolumn{2}{|c|}{$\begin{array}{c}-0.002 * \\
(0.001)\end{array}$} & \multicolumn{2}{|r|}{$\begin{array}{c}-0.002 * * \\
(0.001)\end{array}$} \\
\hline Mediation ratio & \multicolumn{2}{|c|}{ Complete } & \multicolumn{2}{|c|}{ Complete } & \multicolumn{2}{|r|}{ Complete } \\
\hline
\end{tabular}

Table 5. Mediation analysis based on standardized regression weights from simultaneous equation modeling with SSCBs_freq as a mediator (for the entire sample).

\begin{tabular}{|c|c|c|c|c|c|c|}
\hline \multirow[b]{2}{*}{ Variables $^{1}$} & \multicolumn{2}{|c|}{1.} & \multicolumn{2}{|c|}{2.} & \multicolumn{2}{|r|}{3.} \\
\hline & SSCBs_freq & $\begin{array}{l}\text { BMI-for-Age } \\
\text { z-Score }\end{array}$ & SSCBs_freq & $\begin{array}{c}\text { Overweight } \\
\text { (=1 if Yes) }\end{array}$ & SSCBs_freq & Obesity (=1 if Yes) \\
\hline DK & $-0.040^{* * *}$ & 0.003 & $-0.040^{* * *}$ & 0.003 & $-0.035^{* * *}$ & 0.004 * \\
\hline \multirow{2}{*}{ SSCBs_freq } & $\begin{array}{c}(0.007) \\
-\end{array}$ & $\begin{array}{c}(0.007) \\
0.204^{* * *}\end{array}$ & $\begin{array}{c}(0.007) \\
-\end{array}$ & $\begin{array}{c}(0.002) \\
0.110^{* * *}\end{array}$ & $\begin{array}{c}(0.008) \\
-\end{array}$ & $\begin{array}{c}(0.002) \\
0.136^{* * *}\end{array}$ \\
\hline & - & $(0.079)$ & - & $(0.028)$ & - & $(0.024)$ \\
\hline Control variables & Yes & Yes & Yes & Yes & Yes & Yes \\
\hline Observations & 3949 & 3949 & 3840 & 3840 & 3130 & 3130 \\
\hline R-squared/Chi2 & $0.02 / 97.6$ & $0.02 / 292.7$ & $0.02 / 96.4$ & $-0.05 / 284.8$ & $0.02 / 72.9$ & $-0.23 / 285.0$ \\
\hline Mediated effect $\left(\alpha^{*} \beta\right)$ & \multicolumn{2}{|c|}{$\begin{array}{c}-0.008 * * \\
(0.003)\end{array}$} & \multicolumn{2}{|c|}{$\begin{array}{c}-0.004^{* * *} \\
(0.001)\end{array}$} & \multicolumn{2}{|r|}{$\begin{array}{c}-0.005^{* * *} \\
(0.001)\end{array}$} \\
\hline Mediation ratio & \multicolumn{2}{|c|}{ Complete } & \multicolumn{2}{|c|}{ Complete } & \multicolumn{2}{|r|}{ Partial } \\
\hline
\end{tabular}

Then, mediation effects are identified by the standardized regression coefficients from 3SLS analysis. Generally, a given variable may be said to act as a mediator to the extent that it accounts for the relation between the dependent variable and the independent variable [49]. The mediating effect is generally calculated by the product-of-coefficients approach $[50,51]$, which determines the mediation by multiplying the regression coefficients $(\alpha \cdot \beta)$. It also needs to obtain the standard error of $\alpha \cdot \beta$, by dividing the product of the 
coefficients $\alpha$ and $\beta$ by its standard error $\left(S E_{\alpha \beta}=\sqrt{\alpha^{2} \cdot S E_{\beta}^{2}+\beta^{2} \cdot S E_{\alpha}^{2}}\right)$, to evaluate the statistical significance of the mediation effect. The coefficient $\gamma$ represents the direct influence of DK on health outcome indicators. Complete mediation indicates that the mediator can fully explain the effects of the direct influence (do not reject the null hypothesis that $\gamma=0$ ), while partial mediation indicates the mediator can partially explain the direct influence (reject the null hypothesis that $\gamma=0$ at the characteristic significance level).

\section{Results}

\subsection{Descriptive Analysis}

\subsubsection{Descriptive Statistics of the Sample}

Table 2 presents summary statistics of all of the variables used in the analysis. As presented in Table 2, the average BMI-for-age z-score was 0.33 among the entire sample. Almost one-third were overweight and obese, and more than half were obese. The overweight and obesity rate of children in the Inner Mongolia Autonomous Region is indeed at a high epidemic level.

The score of DK ranged from 1 to 25 . A high score of DK indicated that students had a healthier cognition of the items related to dietary knowledge. The average score of subjective dietary knowledge (DK) was 20.7. Although students' choices may not represent their actual habits, it can still be expected that students' cognition and behavior would be consistent to a certain extent.

As for the consumption of SSCBs, 72.1 percent of the students drank SSCBs in the past week. Per capita and consumer SSCBs intake values were 38.1 (sd 46.1) and 52.8 (sd 46.5) $\mathrm{mL} / \mathrm{d}$, respectively. The average intake of boys was significantly higher than that of girls by $12.6 \mathrm{~mL} / \mathrm{d}$. Per capita and consumer SSCBs consumption frequencies were 1.3 (sd 1.6) and 1.8 (sd 1.6) servings per week, respectively. The average intake of boys was significantly higher than that of girls by 0.3 servings per week. Furthermore, the distribution of BMI among subgroups (grouped by individual and family characteristics) was analyzed and is presented in Section 3.1.2. Since these differences were observed without controlling for potential confounding factors, they can only be interpreted as suggestive. However, these observations still provide us with a useful reference for grouping in the heterogeneity analysis stage.

\subsubsection{The Distribution of BMI-for-Age Z-Score Among Subgroups}

Figure 2 presents the distribution of BMI-for-age z-score for entire sample and subgroups. As presented in Figure 2a, the overall distribution of students BMI-for-age was positioned to the right of the normal distribution, with a relatively flat right tail, which indicates that more were overweight and obese than the standard status. Figure $2 b-f$ shows the distribution of BMI-for-age z-score among subgroups. Compared with the entire distribution, the distributions of both boys and girls were relatively flat, while girls' distributions were slightly steeper than those of boys; the distribution of primary school students was relatively flat, while junior school students' distribution was slightly steep; the distribution of only-child was relatively flat, while that of students with at least was sibling was slightly steep; the distribution of students whose father's and mother's BMIs were normal was slightly steep, that of students with at least one parent with BMI $\geq 25$ was lightly flat, and that of students with at least one parent with BMI $\geq 30$ was flatter. 

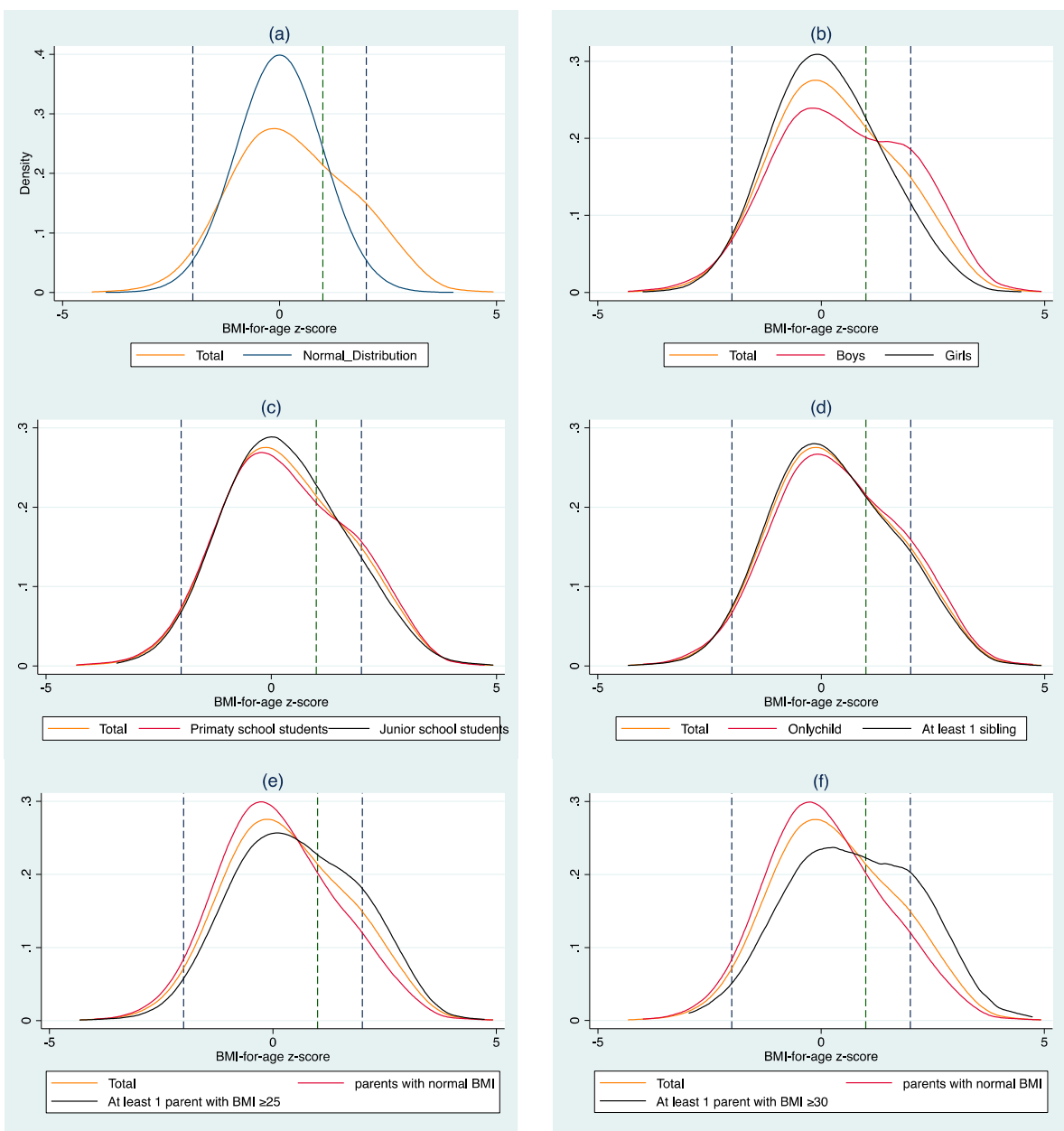

Figure 2. Distribution of body mass index-for-age z-score for entire sample, subgroups, and normal distribution (Mean = 0, Standard deviation $=1$ ). (a): Distribution of BMI-for-age z-score for the entire sample and normal distribution; (b): Distribution of BMI-for-age z-score for the entire sample and subgroups (grouped by gender); (c): Distribution of BMI-for-age z-score for the entire sample and subgroups (grouped by school type); (d): Distribution of BMI-for-age z-score for the entire sample and subgroups (grouped by sibling number); (e,f): Distribution of BMI-for-age z-score for the entire sample and subgroups (grouped by parental health status).

Specifically for boys, the prevalence of overweight and obesity was 40 percent, among which the obesity rate was 25 percent. For girls, the two figures were 24 percent and 9 percent, respectively. For primary school students, the prevalence of overweight and obesity was 33 percent, among which the obesity rate was 18 percent; for junior school students, the two figures were 29 percent and 14 percent, respectively. For only-child, the prevalence of overweight and obesity was 34 percent, among which the obesity rate was 19 percent; for students with at least one sibling, the two figures were 30 percent and 15 percent, respectively. For students whose father's and mother's BMI were both normal $(18.5 \leq$ BMI_father $<25$ and $18.5 \leq$ BMI_mother $<25)$, the prevalence of overweight and obesity was 26 percent, among which the obesity rate was 11 percent; for students with at least one parent with BMI $\geq 25$ (BMI_father $\geq 25$ or BMI_mother $\geq 25$ ), the two figures were 38 percent and 22 percent, respectively; for students with at least one parent with BMI $\geq 30$ (BMI_father $\geq 30$ or BMI_mother $\geq 30$ ), the two figures were 44 percent and 28 percent, respectively. The prevalence of boys, junior school students, only-child, students having at least one parent with $B M I \geq 25$, and students having at least one parent with $\mathrm{BMI} \geq 30$ was significantly higher than that of the compared subgroups (Table 3 ). 


\subsection{Systematic Analysis of a Hypothetical Mediational Model}

As seen in Tables 4 and 5, the results showed a significant negative relationship between DK and SSCBs consumption indicators (SSCBs_mL and SSCBs_freq) but a positive correlation between SSCBs consumption indicators and health outcomes (overweight and obesity). Specifically, the results in Table 4 suggest that for the model of overweight with SSCBs_mL as a mediator, for every 1-point gain in DK, the consumption of SSCBs per day significantly decreased by $0.806 \mathrm{~mL} / \mathrm{d}(p<0.01)$. Further, for every $1-\mathrm{mL} / \mathrm{d}$ gain in SSCBs_mL, the incidence of overweight increased by $0.002 \mathrm{sd}(p<0.05)$. For the model of obesity with SSCBs_mL as a mediator, a 1-point increase in DK was negatively associated with a $0.542 \mathrm{~mL} / \mathrm{d}(p<0.05)$ reduction in SSCBs_mL, while a $1-\mathrm{mL} / \mathrm{d}$ increase in SSCBs_mL was associated with a 0.004 sd increase in the obesity ratio $(p<0.01)$.

The results in Table 5 suggest that for the model of overweight with SSCBs_freq as a mediator, for every 1-point gain in DK, the consumption frequency of SSCBs per week significantly decreased by 0.04 drinks $/ \mathrm{w}(p<0.01)$. Further, for every 1-drink/w gain in SSCBs_freq, the incidence of overweight increased by $0.204 \mathrm{sd}(p<0.01)$. For the model of obesity with SSBCs_freq as a mediator, a 1-point increase in DK was negatively associated with a 0.35 drink/w $(p<0.05)$ reduction in SSCBs_freq, while a 1-drink/w increase in SSCBs_freq was associated with a 0.136 sd increase in the obesity ratio $(p<0.01)$.

Table 4 presents the mediated effect of the indicator SSCBs consumption per day, while Table 5 presents that of the indicator SSCBs consum ption frequency per week. Both of the indicators mediated the relationship between subjective dietary knowledge and health outcomes, and SSCBs_freq had the stronger mediating effect. Specifically, with SSCBs_mL as a mediator, a 1-point increase in DK was associated with a 0.0019 sd decrease in the overweight ratio $(p<0.10)$ and a 0.0021 sd decrease in the obesity ratio $(p<0.05)$. With SSCBs_freq as a mediator, a 1-point increase in DK was associated with a $0.0044 \mathrm{sd}(p<0.01)$ and $0.0047 \mathrm{sd}(p<0.01)$ decrease in the overweight and obesity ratio, respectively.

\subsection{Heterogeneous Effect of Mediation}

The statistical analysis mentioned in Sections 2.2.1 and 2.2.3 showed significant differences in the BMI-for-age z-score distribution, consumption of SSCBs, or consumption frequency of SSCBs among subgroups divided by personal/family characteristics (such as gender, school type, sibling number, and parental health status). Some personal and family characteristics appeared to be effective moderators. To gain a deeper understanding, the present paper analyzed the heterogeneity effect of mediation by gender subgroups. Table 6 presented the direct effects on the health outcomes $(\gamma)$ and hypothetical mediators $(\alpha)$ and the effect of the mediator on the outcome $(\beta)$ for the SSCBs consumption indicators for each subgroup. The mediated effect $\left(\alpha^{*} \beta\right)$ for each indicator per subgroup was computed.

For the relationship of "Dietary knowledge with Overweight", no significant mediated effect was found in subgroups of boys, junior school students, students whose father's and mother's BMI were normal (18.5 $\leq$ BMI_father $<25$ and $18.5 \leq$ BMI_mother $<25)$, and students with at least one parent with BMI $\geq 30$ (BMI_father $\geq 30$ or BMI_mother $\geq 30$ ). Small but significant complete mediated effects were found in subgroups of girls, students with no sibling, and students with at least one parent with BMI $\geq 25$ (BMI_father $\geq 25$ or BMI_mother $\geq 25$ ). Specifically, among girls or students with at least one parent with BMI $\geq 25$, the complete mediated effect values of SSCBs_mL and SSCBs_freq were $0.004 \mathrm{sd}$ $(p<0.05)$ and 0.005 sd $(p<0.01)$, respectively; among students with no sibling, the values were $0.004 \mathrm{sd}(p<0.05)$ and $0.005 \mathrm{sd}(p<0.05)$, respectively. Partial mediated effects were found in subgroups of primary school students and students with at least one sibling. Specifically, among primary school students, the partial mediated effect values of SSCBs_mL and SSCBs_freq were $0.008 \mathrm{sd}(p<0.01)$ and $0.007 \mathrm{sd}(p<0.01)$, respectively; among students with at least one sibling, the mediating effect value of SSCBs_freq was $0.003 \mathrm{sd}(p<0.05)$. 
Table 6. Mediation analysis based on standardized regression weights from simultaneous equation modeling (for subgroups).

\begin{tabular}{|c|c|c|c|c|c|c|c|c|}
\hline Relationship & & Subgroup & Mediator & $\begin{array}{l}\text { Direct Effect with } \\
\text { Mediator }(\gamma)\end{array}$ & $\begin{array}{c}\text { Dietary } \\
\text { Knowledge on } \\
\text { Mediator }(\alpha)\end{array}$ & $\begin{array}{c}\text { Mediator on Health } \\
\text { Outcome }(\beta)\end{array}$ & $\begin{array}{c}\text { Mediated } \\
\text { Effect }\left(\alpha^{*} \beta\right)\end{array}$ & Mediation \\
\hline \multirow{18}{*}{$\begin{array}{c}\text { Dietary } \\
\text { Knowledge } \\
\text { with } \\
\text { OverWeight }\end{array}$} & \multirow{4}{*}{ Panel A: Gender } & \multirow{2}{*}{ Boys } & SSCBs_mL & -0.003 & $-0.818^{* *}$ & $-0.002 * *$ & 0.002 & NA \\
\hline & & & SSCBs_freq & -0.003 & $-0.047^{* * *}$ & -0.049 & 0.002 & NA \\
\hline & & \multirow{2}{*}{ Girls } & SSCBs_mL & 0.002 & $-0.822^{* * *}$ & $0.005^{* * *}$ & $-0.004^{* *}$ & Complete \\
\hline & & & SSCBs_freq & 0.003 & $-0.032^{* * *}$ & $0.149^{* * *}$ & $-0.005^{* * *}$ & Complete \\
\hline & \multirow{4}{*}{ Panel B: School type } & \multirow{2}{*}{ Primary school students } & SSCBs_mL & $0.007^{* *}$ & $-0.766^{* * *}$ & $0.010^{* * *}$ & $-0.008^{* * *}$ & Partial \\
\hline & & & SSCBs_freq & $0.006^{* *}$ & $-0.038^{* * *}$ & $0.182 * * *$ & $-0.007^{* * *}$ & Partial \\
\hline & & \multirow{2}{*}{ Junior school students } & SSCBs_mL & -0.005 & $-0.937^{* *}$ & -0.001 & 0.001 & NA \\
\hline & & & SSCBs_freq & -0.003 & $-0.044^{* * *}$ & 0.018 & -0.001 & NA \\
\hline & \multirow{4}{*}{$\begin{array}{l}\text { Panel C: Sibling } \\
\text { number }\end{array}$} & \multirow{2}{*}{ Only-child (no sibling) } & SSCBs_mL & -0.004 & $-1.499^{* * *}$ & $0.003^{* * *}$ & $-0.004^{* *}$ & Complete \\
\hline & & & SSCBs_freq & -0.005 & $-0.054^{* * *}$ & $0.086^{* *}$ & $-0.005^{* *}$ & Complete \\
\hline & & \multirow{2}{*}{ At least one sibling } & SSCBs_mL & 0.003 & $-0.460 *$ & 0.001 & -0.000 & NA \\
\hline & & & SSCBs_freq & $0.006^{* *}$ & $-0.033^{* * *}$ & $0.092^{* * *}$ & $-0.003^{* *}$ & Partial \\
\hline & \multirow{6}{*}{$\begin{array}{l}\text { Panel D: Parental } \\
\text { health status }\end{array}$} & BMI_father $\in[18.5,24.9]$ and & SSCBs_mL & -0.001 & -0.230 & 0.000 & -0.000 & NA \\
\hline & & BMI_mother $\in[18.5,24.9]$ & SSCBs_freq & -0.001 & $-0.032^{* * *}$ & 0.014 & -0.000 & NA \\
\hline & & BMI_father $\geq 25$ or & SSCBs_mL & 0.002 & $-1.282^{* * *}$ & $0.003 * *$ & $-0.004^{* *}$ & Complete \\
\hline & & BMI_mother $\geq 25$ & SSCBs_freq & 0.004 & $-0.041^{* * *}$ & $0.131^{* * *}$ & $-0.005^{* * *}$ & Complete \\
\hline & & BMI_father $\geq 30$ or & SSCBs_mL & 0.000 & $-1.633 *$ & $0.006^{* * *}$ & -0.009 & NA \\
\hline & & BMI_mother $\geq 30$ & SSCBs_freq & 0.002 & -0.052 & $0.203 * * *$ & -0.010 & NA \\
\hline \multirow{8}{*}{$\begin{array}{l}\text { Dietary } \\
\text { knowledge with } \\
\text { Obesity }\end{array}$} & \multirow{4}{*}{ Panel A: Gender } & \multirow{2}{*}{ Boys } & SSCBs_mL & 0.001 & -0.505 & $0.002 *$ & -0.001 & NA \\
\hline & & & SSCBs_freq & 0.002 & $-0.038^{* * *}$ & 0.045 & -0.002 & NA \\
\hline & & \multirow{2}{*}{ Girls } & SSCBs_mL & 0.000 & $-0.614^{* *}$ & $0.006^{* * *}$ & $-0.004^{* *}$ & Complete \\
\hline & & & SSCBs_freq & 0.001 & $-0.031^{* * *}$ & $0.149^{* * *}$ & $-0.005^{* * *}$ & Complete \\
\hline & \multirow{4}{*}{ Panel B: School type } & \multirow{2}{*}{ Primary school students } & SSCBs_mL & 0.003 & $-0.471 *$ & $0.011^{* * *}$ & $-0.005^{*}$ & Complete \\
\hline & & & SSCBs_freq & 0.005 * & $-0.034^{* * *}$ & $0.182 * * *$ & $-0.006^{* * *}$ & Partial \\
\hline & & \multirow{2}{*}{ Junior school students } & SSCBs_mL & -0.002 & -0.673 & 0.001 & -0.001 & NA \\
\hline & & & SSCBs_freq & 0.002 & $-0.034^{* *}$ & $0.131^{* * *}$ & $-0.004^{* *}$ & Complete \\
\hline
\end{tabular}


Table 6. Cont.

\begin{tabular}{|c|c|c|c|c|c|c|c|c|}
\hline Relationship & & Subgroup & Mediator & $\begin{array}{l}\text { Direct Effect with } \\
\text { Mediator }(\gamma)\end{array}$ & $\begin{array}{c}\text { Dietary } \\
\text { Knowledge on } \\
\text { Mediator }(\alpha)\end{array}$ & $\begin{array}{c}\text { Mediator on Health } \\
\text { Outcome }(\beta)\end{array}$ & $\begin{array}{c}\text { Mediated } \\
\text { Effect }\left(\alpha^{*} \beta\right)\end{array}$ & Mediation \\
\hline & $\begin{array}{c}\text { Panel C: Sibling } \\
\text { number }\end{array}$ & $\begin{array}{l}\text { Only-child } \\
\text { At least one sibling }\end{array}$ & $\begin{array}{l}\text { SSCBs_mL } \\
\text { SSCBs_freq } \\
\text { SSCBs_mL } \\
\text { SSCBs_freq }\end{array}$ & $\begin{array}{c}-0.003 \\
-0.002 \\
0.001 \\
0.005^{*}\end{array}$ & $\begin{array}{l}-1.472^{* * *} \\
-0.048^{* * *} \\
-0.101 \\
-0.028^{* * *}\end{array}$ & $\begin{array}{c}-0.000 \\
0.031 \\
0.004^{* * *} \\
0.162^{* * *}\end{array}$ & $\begin{array}{c}0.000 \\
-0.001 \\
-0.000 \\
-0.005^{* *}\end{array}$ & $\begin{array}{l}\text { NA } \\
\text { NA } \\
\text { NA } \\
\text { Partial }\end{array}$ \\
\hline & $\begin{array}{l}\text { Panel D: Parental } \\
\text { health status }\end{array}$ & $\begin{array}{c}\text { BMI_father } \in[18.5,24.9] \text { and } \\
\text { BMI_mother } \in[18.5,24.9] \\
\text { BMI_father }>=25 \text { or } \\
\text { BMI_mother }>=25 \\
\text { BMI_father }>=30 \text { or } \\
\text { BMI_mother }>=30\end{array}$ & $\begin{array}{l}\text { SSCBs_mL } \\
\text { SSCBs_freq } \\
\text { SSCBs_mL } \\
\text { SSCBs_freq } \\
\text { SSCBs_mL } \\
\text { SSCBs_freq }\end{array}$ & $\begin{array}{c}-0.002 \\
0.001 \\
0.001 \\
0.002 \\
0.007 \\
0.002\end{array}$ & $\begin{array}{l}-0.071 \\
-0.029^{* * *} \\
-0.916^{* * *} \\
-0.031^{* * *} \\
-2.149^{* *} \\
-0.043\end{array}$ & $\begin{array}{c}0.001 \\
0.076^{* * *} \\
0.003^{* *} \\
0.131^{* * *} \\
0.006^{* * *} \\
0.185^{* * *}\end{array}$ & $\begin{array}{l}-0.000 \\
-0.002^{* *} \\
-0.003^{* *} \\
-0.004^{* *} \\
-0.014^{*} \\
0.008\end{array}$ & $\begin{array}{c}\text { NA } \\
\text { Complete } \\
\text { Complete } \\
\text { Complete } \\
\text { Complete } \\
\text { NA }\end{array}$ \\
\hline
\end{tabular}

${ }^{1}$ Robust standard errors in parentheses. ${ }^{* * *} p<0.01,{ }^{* *} p<0.05,{ }^{*} p<0.1$. Source: Authors' survey. $\left({ }^{2}\right)$ NA $=$ Not applicable. 
For the relationship of "Dietary knowledge with Obesity", no significant mediated effect is found in subgroups of boys and students with no sibling. Small but significant complete mediated effects were found in subgroups of girls, primary school students, junior school students, and students with any type of parental health status. Specifically, among girls, the complete mediated effect values of SSCBs_mL and SSCBs_freq were $0.004 \mathrm{sd}(p<0.05)$ and $0.005 \mathrm{sd}(p<0.01)$, respectively; among primary school students and students with at least one parent with $\mathrm{BMI} \geq 30$, the complete mediating effect values of SSCBs_mL were $0.005 \mathrm{sd}(p<0.1)$ and $0.014 \mathrm{sd}(p<0.1)$, respectively; among junior school students and students whose father's and mother's BMI were normal, the complete mediating effect values of SSCBs_freq were $0.004 \mathrm{sd}(p<0.05)$ and $0.002(p<0.05)$, respectively; among students with at least one parent with BMI $\geq 25$, the complete mediated effect values of SSCBs_mL and SSCBs_freq were $0.003 \mathrm{sd}(p<0.05)$ and $0.004 \mathrm{sd}$ $(p<0.01)$, respectively. Partial mediated effects were found in subgroups of primary school students and students with at least one sibling, with SSCBs_freq as a mediator. Specifically, among primary school students, the partial mediated effect value of SSCBs_freq was $0.006 \mathrm{sd}(p<0.01)$; among students with at least one sibling, the mediating effect value of SSCBs_freq was $0.005 \mathrm{sd}(p<0.05)$.

\section{Discussion}

The prevalence of overweight and obesity among children and in the Inner Mongolia Autonomous Region is at a high level. As a high-endemic area of overweight and obesity among children and adolescents in China, the prevalence of overweight and obesity in the Inner Mongolia Autonomous Region is 13 percent higher than the national average (19 percent in the 6-17-year age group). In particular, the prevalence of overweight and obesity among boys in this region is twice the national average. This may represent the average level of twelve high-endemic areas of overweight and obesity among children in China, which has exceeded the overweight and obesity rates of children in some highincome countries, such as Australia [6]. The findings of this article provide the recent status of SSCBs consumption of a regionally representative sample of Inner Mongolian children and adolescents. Although the proportion of children in Inner Mongolia consuming SSCBs is relatively high (72.1 percent), the per capita intake is relatively low, $38.1 \mathrm{~mL}$ per day (sd 46.1) or 1.3 drinks per week (sd 1.6). Since the proportion of sugar per unit weight of SSCBs is 12 percent in China [52], by multiplying the average daily consumption of SSCBs by the proportion of added sugar in SSCBs, the per capita added-sugar intake derived from SSCBs was calculated as 4.6 grams per day. This finding is consistent with a previous study conducted in China on SSBs consumption among children and adolescents aged 6-17 years [27] but contradicts the findings of children in high-income countries. For example, in Australia, although the daily intake of added-sugar from SSCBs is nearly four times that of Chinese children in the present study, the proportion of children and adolescents who consumed SSCBs was less than 50 percent [53].

SSBs are a major contributor to children's added sugar consumption. Although in clinical trials and epidemiological studies, evidence for an association between sugar consumption and weight gain is inconclusive [54], there is growing evidence that a reduction in SSBs consumption would result in a proportional decrease in the prevalence of overweight and obesity $[22,24,29,30]$. In China, studies have shown that regular consumption of SSBs, especially SSCBs, is positively correlated with overweight and obesity among children [27,35-37], but there are differences in the selection of obesity indicators. Some believe that SSBs consumption is independently associated with a high risk of abdominal obesity in children and adolescents, but not with general obesity [27]. Some reported that SSBs consumption is positively correlated with general obesity [36,37]; others reported that SSBs consumption is positively correlated with both abdominal obesity and obesity [35]. In the present study, there was a small but significant positive correlation between the consumption of SSCBs and the prevalence of both overweight and obesity. These correlation coefficients for girls were more significant and higher in absolute value than those of boys, 
although girls' consumption and SSCBs consumption frequency were significantly lower than those of boys'. These correlation coefficients for primary school students were more significant and higher in absolute value than those of junior school students, which may be because most of the primary school students in the sample were younger than 12 (in childhood or early adolescence) when they participated in the survey. Compared with the relatively older junior high school students, they have different metabolic characteristics, and their BMI-for-age z-score is more likely to be impacted by SSCBs consumption.

Although taxing SSBs to improve population health outcomes has appeared as an effective intervention to address the rising prevalence of obesity in both high- and middleincome countries [29-34], there is no evidence that it can reduce the population overweight and obese risk permanently. Besides, the specific effects on tax fairness and health promotion are still being demonstrated, and a unified evaluation system to monitor the property and sustainability of taxes on SSBs is lacking. In China, the public opinion support environment for taxation of sugary beverages has not yet been formed, and the corresponding publicity and science education is still in its infancy. If a tax on sugary drinks is rashly imposed, it would inevitably arouse public doubts, and the consequences are unpredictable. In Chinese Confucianism, there is a concept of "taking preventive measures", which means to prevent disasters before they happen. Some intervention experiments in children showed that behavioral intervention could reduce children's sugar intake, but they had low compliance to dietary advice. Nutritional education, such as courses on general health issues and common advice on healthy diets, may not affect children's behavior in the short term $[23,55]$. Another experiment to reduce children's consumption of SSBs by instituting an educational course (for a period of six months) showed that primary school students are receptive to information on healthy diets, and adding educational programs to the primary school curriculum may help reduce the consumption of SSBs in the long term [56]. Since it is parents or caregivers, especially female roles, who decide what food to purchase for household consumption, their dietary knowledge might indirectly affect children's behavior. However, although no studies have shown that female education has no effect on children's nutrition, it cannot be assumed that there is a positive linear relationship between the two in some cases [57]. In China, although some studies evaluated the effects of comprehensive childhood obesity interventions on dietary intake among children [58], there is no relevant research on interventions in the consumption of SSCBs.

In the present paper, the estimation results of the hypothetical mediational models showed that the mediation effects of the two SSBC consumption indicators were small but significant. The results suggest that improving dietary knowledge related to the lowing of SSBs consumption to reduce the obesity risk may be considered a possible way to reduce the prevalence of overweight and obesity among children. These pathways of influence may have more obvious effects on younger children, since the mediation coefficients for primary school students were more significant and higher in absolute value than those for junior school students. This may be because compared with junior high school students, primary school students are still in the stage of cognitive formation, and their cognitive level and behavioral consistency are higher. Besides, the heterogeneity effect of mediation by gender subgroups indicated that the mediation coefficients for girls were more significant and higher in absolute value than those for boys. This may be because Chinese girls pay more attention to their appearance and diet compared with boys. Obesity prevention in children should be gender-focused, particularly for girls who reported SSCBs consumption but had a lower prevalence of obesity, even though more boys were overweight or obese than girls. Evidence with data from three large cohorts (i.e., Nurses' Health Study, Health Professionals' Follow-up Study, and Women's Genome Health Study) suggests that regular consumption of SSBs exacerbates the genetic risk of obesity [24]. Moreover, as seen in this study, for students with at least one parent with $\mathrm{BMI} \geq 30$, it is no longer possible to influence the incidence of overweight and obesity by adjusting dietary knowledge and SSCBs consumption. Considering the individual differences in metabolic reactions to the intake of SSBs and the gender differences in the 
pathways of influence, the improvement of girls' weight status and the accumulation of dietary knowledge may be passed on to the next generation, thereby permanently reducing the prevalence of obesity in the population.

To the best of our knowledge, the present study is the first to explore potential ways to reduce the incidence of overweight and obesity by reducing SSCBs consumption among 9-15 year-olds in China. The conclusions of this paper may enable Chinese policy-makers to design more targeted and cost-effective strategies and interventions to reduce SSBs intake of children and thus to prevent further increases in overweight and obesity prevalence. A more general implication is to lay the foundation for achieving zero growth in overweight and obesity among children and adolescents by providing a reference for policymakers to designate sugar consumption-intervention projects.

It is undeniable that there are some limitations to consider when evaluating the results of this article. First, although the structural equation model solves part of the endogeneity problem, a causal relationship still cannot be established due to the cross-sectional sample. Second, this study was limited to students aged 9-15, and the conclusions may not be applicable to other age groups. Expansion of sample coverage by designing reasonable random intervention experiments or tracking surveys to construct panel data might provide more reliable and generalizable results. Third, due to data limitations, the present paper did not involve students' physical activity status in the analysis. Adding the physical activity module into the questionnaires does help draw more comprehensive conclusions and recommendations on lowering the prevalence of overweight and obesity. However, due to the pressure of schoolwork, Chinese primary and junior high school students did fewer physical activities on a daily basis in the year of this survey and earlier, the physical activity module was not involved in this survey. Despite these facts, the research methods in this paper could still be used by other researchers to study countries or regions with similar sample characteristics and prevalence of overweight and obesity. However, the variable construction method needs to be adjusted appropriately according to the specific sample.

\section{Conclusions}

This paper estimated the possible influential pathway through which students' subjective dietary knowledge may affect the consumption of SSCBs, thereby affecting the occurrence of overweight and obesity. The estimation results of the hypothetical mediational models show that the mediation effects of the two SSBC consumption indicators were small but significant. In particular, SSCBs consumption frequency had a stronger mediating effect than SSCBs consumption quantity. The heterogeneity effect of mediation by subgroups indicated that the mediation coefficients for girls were more significant and higher in absolute value than those for boys, those for primary school students were more significant and higher in absolute value than those for junior school students, and there was no mediated effect for students with at least one parent with BMI $\geq 30$. Considering the heterogeneity between subgroups of mediating effects, public health practitioners and policy makers should adopt a multi-layered nutrition intervention policy to not only strengthen the nutrition education of students, but also to improve the nutrition awareness of parents and school teachers, as well as to strengthen the supervision of children's consumption of SSBs from the perspective of family and society. First, the education department should institute nutrition and health courses in kindergarten and elementary schools to shape healthy nutrition-conscious eating habits from the early childhood stage. Secondly, for adults, especially parents, the health department should promote healthy eating habits such as reducing sugar intake. Encouraging the whole society to participate in healthy eating actions such as reducing salt, oil, and sugar can create a beneficial environment for controlling children's sugar intake. Moreover, the government should stipulate prohibiting the excessive promotion of sugar-sweetened beverage products in social welfare institutions dedicated to serving minors and places that mainly provide education, teaching, and activities for minors. Sellers of carbonated beverages should affix standard reminder labels on shelves or counters related to the nutrition of carbonated 
beverages. The production standards and setting of specifications of relevant reminder slogans should be formulated by the local health department and announced to the public. These steps will make important contributions to reducing the epidemic of overweight and obesity among children and adolescents.

Author Contributions: Data curation, Z.L., Q.Z., and C.T.; formal analysis, Z.L., W.S., Q.Z., and C.T.; funding acquisition, W.S., Q.Z.; investigation, Z.L., Q.Z., and C.T.; methodology, Q.Z. and C.T.; project administration, W.S. and Q.Z.; resources, Z.L. and W.S.; software, Q.Z. and C.T.; writingoriginal draft, Z.L., Q.Z., and C.T.; writing-review and editing, Z.L., W.S., Q.Z., and C.T. All authors have read and agreed to the published version of the manuscript.

Funding: This research was funded by the National Natural Science Foundation of China, grant numbers 71973136 and 71773122; Research Innovation Fund for Graduate Students of China Agriculture University, grant number 2020XYZC05B; The 2115 Talent Development Program of China Agricultural University.

Institutional Review Board Statement: The study received ethical approval from the China Agricultural University Institutional Review Board, and all procedures performed in studies involving human participants were following the 1964 Helsinki declaration and its later amendments.

Informed Consent Statement: Informed consent was obtained from all subjects involved in the study.

Data Availability Statement: The data presented in this study are available on request from the corresponding author. The data are not publicly available due to ethical.

Conflicts of Interest: The authors declare no conflict of interest.

\section{Appendix A}

Table A1. The subjective dietary knowledge module of the questionnaire for students.

\section{* Ask the Respondent if He or She Strongly Agrees, Somewhat Agrees, Neutral, Somewhat Disagrees or Strongly Disagrees} with Each Statement in Item 2 and Record the Answers in Table I5. Table I5. Dietary Knowledge

12

\section{Statement}

Please use 1-5 to describe if you strongly disagree, somewhat disagree, neutral, somewhat agree, or strongly agree with this statement.

* Please note that the question is not asking about your actual habits.
1 strongly disagree

2 disagree

3 neutral

4 agree

5 strongly agree 0 unknown

Choosing a diet with a lot of fresh fruits and vegetables is good for one's health.

Eating a lot of sugar is good for one's health.

I5-1.

Consuming milk and dairy products is good for one's health

The heavier one's body is, the healthier he or she is.

-I5-3.

I5-4.

The development of good eating habits is very beneficial to health

\section{References}

1. WHO. World Health Statistics 2020: Monitoring Health for the SDGs, Sustainable Development Goals; World Health Organization: Geneva, Switzerland, 2020.

2. Roberto, C.A.; Swinburn, B.; Hawkes, C.; Huang, T.T.K.; Costa, S.A.; Ashe, M.; Zwicker, L.; Cawley, J.H.; Brownell, K.D. Patchy progress on obesity prevention: Emerging examples, entrenched barriers, and new thinking. Lancet 2015, 385, 2400-2409. [CrossRef]

3. IFPRI. Global Nutrition Report 2016: From Promise to Impact: Ending Malnutrition by 2030; International Food Policy Research Institute: Washington, DC, USA, 2016. [CrossRef]

4. WHO. Obesity and Overweight. Available online: https://www.who.int/news-room/fact-sheets/detail/obesity-andoverweight (accessed on 30 December 2020).

5. Hales, C.M.; Carroll, M.D.; Fryar, C.D.; Ogden, C.L. Prevalence of Obesity Among Adults and Youth: United States, 2015-2016. NCHS Data Brief 2017, No.288, 1-7. 
6. AIHW. Overweight and Obesity among Australian Children and Adolescents; AIHW: Canberra, Australia, 2020.

7. Spinelli, A.; Buoncristiano, M.; Kovacs, V.A.; Yngve, A.; Spiroski, I.; Obreja, G.; Starc, G.; Pérez, N.; Rito, A.I.; Kunešová, M. Prevalence of severe obesity among primary school children in 21 European countries. Obes. Facts 2019, 12, 244-258. [CrossRef]

8. Li, L.M.; Rao, K.Q.; Kong, L.Z.; Yao, C.H.; Xiang, H.D.; Zhai, F.Y.; Yang, X.G. A description on the Chinese national nutrition and health survey in 2002. Chin. J. Epidemiol. 2005, 27, 478-484. (In Chinese)

9. Blüher, M. Obesity: Global epidemiology and pathogenesis. Nat. Rev. Endocrinol. 2019, 15, 288-298. [CrossRef]

10. Zhang, J.; Wang, H.; Wang, Y.; Xue, H.; Wang, Z.; Du, W.; Su, C.; Zhang, J.; Jiang, H.; Zhai, F. Dietary patterns and their associations with childhood obesity in China. Br. J. Nutr. 2015, 113, 1978-1984. [CrossRef]

11. Salehi-Abargouei, A.; Akbari, F.; Bellissimo, N.; Azadbakht, L. Dietary diversity score and obesity: A systematic review and meta-analysis of observational studies. Eur. J. Clin. Nutr. 2016, 70, 1-9. [CrossRef]

12. Amirhamidi, Z.; Omidvar, N.; Eini-Zinab, H.; Doustmohammadian, A.; Esfandiari, S.; Azadi, R.; Haidari, H. Association of Weight Status with Dietary Intake and Dietary Diversity Score in 10-12-Year-Old Children in Tehran: A Cross-Sectional Study. Iran. J. Pediatrics 2019, 29, 1-11. [CrossRef]

13. Tao, C.; Zhao, Q.; Glauben, T.; Ren, Y. Does dietary diversity reduce the risk of obesity? Empirical evidence from rural school children in China. Int. J. Environ. Res. Public Health 2020, 17, 8122. [CrossRef]

14. Ells, L.J.; Rees, K.; Brown, T.; Mead, E.; Al-Khudairy, L.; Azevedo, L.; McGeechan, G.J.; Baur, L.; Loveman, E.; Clements, H. Interventions for treating children and adolescents with overweight and obesity: An overview of Cochrane reviews. Int. J. Obes. 2018, 42, 1823-1833. [CrossRef]

15. Li, L.; Shen, T.; Wen, L.M.; Wu, M.; He, P.; Wang, Y.; Qu, W.; Tan, H.; He, G. Lifestyle factors associated with childhood obesity: A cross-sectional study in Shanghai, China. BMC Res. Notes 2015, 8, 6. [CrossRef] [PubMed]

16. Williams, E.P.; Mesidor, M.; Winters, K.; Dubbert, P.M.; Wyatt, S.B. Overweight and obesity: Prevalence, consequences, and causes of a growing public health problem. Curr. Obes. Rep. 2015, 4, 363-370. [CrossRef] [PubMed]

17. Schmitz, K.H.; Lytle, L.A.; Phillips, G.A.; Murray, D.M.; Birnbaum, A.S.; Kubik, M.Y. Psychosocial correlates of physical activity and sedentary leisure habits in young adolescents: The Teens Eating for Energy and Nutrition at School study. Prev. Med. 2002, 34, 266-278. [CrossRef] [PubMed]

18. Puder, J.; Munsch, S. Psychological correlates of childhood obesity. Int. J. Obes. 2010, 34, S37-S43. [CrossRef] [PubMed]

19. Bi, J.; Liu, C.; Li, S.; He, Z.; Chen, K.; Luo, R.; Wang, Z.; Yu, Y.; Xu, H. Dietary diversity among preschoolers: A cross-sectional study in poor, rural, and ethnic minority areas of central south china. Nutrients 2019, 11, 558. [CrossRef]

20. The Regional Office for Europe of the World Health Organization. Mapping the Health System Response to Childhood Obesity in the WHO European Region: An Overview and Country Perspectives. 2019. Available online: https://www.euro.who.int/_ data/assets/pdf_file/0019/401176/Childhood-obesity-web.pdf (accessed on 31 December 2020).

21. WHO. World Health Statistics Overview 2019: Monitoring Health for the SDGs, Sustainable Development Goals; World Health Organization: Geneva, Switzerland, 2019.

22. Malik, V.S.; Pan, A.; Willett, W.C.; Hu, F.B. Sugar-sweetened beverages and weight gain in children and adults: A systematic review and meta-analysis. Am. J. Clin. Nutr. 2013, 98, 1084-1102. [CrossRef]

23. Te Morenga, L.; Mallard, S.; Mann, J. Dietary sugars and body weight: Systematic review and meta-analyses of randomised controlled trials and cohort studies. BMJ 2013, 346, e7492. [CrossRef]

24. Hu, F.B. Resolved: There is sufficient scientific evidence that decreasing sugar-sweetened beverage consumption will reduce the prevalence of obesity and obesity-related diseases. Obes. Rev. 2013, 14, 606-619. [CrossRef]

25. Luger, M.; Lafontan, M.; Bes-Rastrollo, M.; Winzer, E.; Yumuk, V.; Farpour-Lambert, N. Sugar-sweetened beverages and weight gain in children and adults: A systematic review from 2013 to 2015 and a comparison with previous studies. Obes. Facts 2017, 10, 674-693. [CrossRef]

26. Ma, G. China Children's Sugary Beverage Consumption Report; People's Medical Publishing House: Beijing, China, 2018. (In Chinese)

27. Gui, Z.-H.; Zhu, Y.-N.; Cai, L.; Sun, F.-H.; Ma, Y.-H.; Jing, J.; Chen, Y.-J. Sugar-sweetened beverage consumption and risks of obesity and hypertension in Chinese children and adolescents: A national cross-sectional analysis. Nutrients 2017, 9, 1302. [CrossRef]

28. WHO. Guideline: Sugars Intake for Adults and Children; World Health Organization: Geneva, Switzerland, 2015.

29. Saxena, A.; Koon, A.D.; Lagrada-Rombaua, L.; Angeles-Agdeppa, I.; Johns, B.; Capanzana, M. Modelling the impact of a tax on sweetened beverages in the Philippines: An extended cost-effectiveness analysis. Bull. World Health Organ. 2019, 97, 97-107. [CrossRef] [PubMed]

30. Nakhimovsky, S.S.; Feigl, A.B.; Avila, C.; O'Sullivan, G.; Macgregor-Skinner, E.; Spranca, M. Taxes on Sugar-Sweetened Beverages to Reduce Overweight and Obesity in Middle-Income Countries: A Systematic Review. PLoS ONE 2016, 11, e0163358. [CrossRef]

31. Lal, A.; Mantilla-Herrera, A.M.; Veerman, L.; Backholer, K.; Sacks, G.; Moodie, M.; Siahpush, M.; Carter, R.; Peeters, A. Modelled health benefits of a sugar-sweetened beverage tax across different socioeconomic groups in Australia: A cost-effectiveness and equity analysis. PLoS Med. 2017, 14, e1002326. [CrossRef] [PubMed]

32. Schwendicke, F.; Stolpe, M. Taxing sugar-sweetened beverages: Impact on overweight and obesity in Germany. BMC Public Health 2017, 17, 88. [CrossRef] [PubMed]

33. Long, M.W.; Gortmaker, S.L.; Ward, Z.J.; Resch, S.C.; Moodie, M.L.; Sacks, G.; Swinburn, B.A.; Carter, R.C.; Claire Wang, Y. Cost Effectiveness of a Sugar-Sweetened Beverage Excise Tax in the U.S. Am. J. Prev. Med. 2015, 49, 112-123. [CrossRef] [PubMed] 
34. WHO. Fiscal policies for diet and the prevention of noncommunicable diseases. In Proceedings of the Fiscal Policies for Diet and the Prevention of Noncommunicable Diseases-Technical Meeting, Geneva, Switzerland, 5-6 May 2015.

35. Shang, X.W.; Liu, A.L.; Zhang, Q.; Hu, X.Q.; Du, S.M.; Jun, M.; Xu, G.F.; Ying, L.; Guo, H.W.; Lin, D. Report on childhood obesity in China (9): Sugar-sweetened beverages consumption and obesity. Biomed. Environ. Sci. 2012, 25, 125-132.

36. He, B.; Long, W.; Li, X.; Yang, W.; Chen, Y.; Zhu, Y. Sugar-Sweetened Beverages Consumption Positively Associated with the Risks of Obesity and Hypertriglyceridemia Among Children Aged 7-18 Years in South China. J. Atheroscler. Thromb. 2018, 25, 81-89. [CrossRef] [PubMed]

37. Yu, P.; Chen, Y.; Zhao, A.; Bai, Y.; Zheng, Y.; Zhao, W.; Zhang, Y. Consumption of sugar-sweetened beverages and its association with overweight among young children from China. Public Health Nutr. 2016, 19, 2336-2346. [CrossRef]

38. NHC-PRC. Implementation Plan for Child and Adolescent Obesity Prevention and Control. Available online: http://www.moe. gov.cn/jyb_xxgk/moe_1777/moe_1779/202010/t20201026_496590.html (accessed on 18 March 2021). (In Chinese)

39. WHO. Growth Reference Data for 5-19 Years/Indicators/BMI-for-age (5-19 Years). Available online: https:/ / www.who.int/ tools/growth-reference-data-for-5to19-years/indicators/bmi-for-age (accessed on 18 March 2021).

40. Onis, M.D.; Onyango, A.W.; Borghi, E.; Siyam, A.; Nishida, C.; Siekmann, J. Development of a WHO growth reference for school-aged children and adolescents. Bull. World Health Organ. 2007, 85, 660-667. [CrossRef]

41. De Onis, M.; Lobstein, T. Defining obesity risk status in the general childhood population: Which cut-offs should we use? Int. J. Pediatr. Obes. 2010, 5, 458-460. [CrossRef]

42. CHNS. China Economic, Population, Nutrition, and Health Survey 2011 Child Questionnaire (For All Children Age 0-17.99). Available online: https://www.cpc.unc.edu/projects/china/data/questionnaires/C11child_Eng.pdf (accessed on 18 March 2021).

43. Liu, W.; Liu, W.; Lin, R.; Li, B.; Pallan, M.; Cheng, K.; Adab, P. Socioeconomic determinants of childhood obesity among primary school children in Guangzhou, China. BMC Public Health 2016, 16, 482. [CrossRef] [PubMed]

44. Chen, Q.; Pei, C.; Zhao, Q. Eating More but Not Better at School? Impacts of Boarding on Students' Dietary Structure and Nutritional Status in Rural Northwestern China. Sustainability 2018, 10, 2753. [CrossRef]

45. Lazzeri, G.; Pammolli, A.; Pilato, V.; Giacchi, M.V. Relationship between 8/9-yr-old school children BMI, parents' BMI and educational level: A cross sectional survey. Nutr. J. 2011, 10, 76. [CrossRef]

46. He, Q.; Ding, Z.; Fong, D.; Karlberg, J. Risk factors of obesity in preschool children in China: A population-based caseControl study. Int. J. Obes. 2000, 24, 1528-1536. [CrossRef]

47. Zellner, A.; Theil, H. Three-stage least squares: Simultaneous estimation of simultaneous equations. In Henri Theil's Contributions to Economics and Econometrics; Springer: Berlin/Heidelberg, Germany, 1992; pp. 147-178.

48. Zellner, A. Estimators for seemingly unrelated regression equations: Some exact finite sample results. J. Am. Stat. Assoc. 1963, 58, 977-992. [CrossRef]

49. Baron, R.M.; Kenny, D.A. The moderator-mediator variable distinction in social psychological research: Conceptual, strategic, and statistical considerations. J. Personal. Soc. Psychol. 1986, 51, 1173. [CrossRef]

50. Krull, J.L.; MacKinnon, D.P. Multilevel mediation modeling in group-based intervention studies. Eval. Rev. 1999, 23, 418-444. [CrossRef]

51. Preacher, K.J.; Hayes, A.F. Asymptotic and resampling strategies for assessing and comparing indirect effects in multiple mediator models. Behav. Res. Methods 2008, 40, 879-891. [CrossRef]

52. Si, W. Sugar Consumption in China: Structural Changes and Geographical Disparities. China Agric. Univ. J. Soc. Sci. Ed. 2012, 29, 8. (In Chinese) [CrossRef]

53. Brand-Miller, J.C.; Barclay, A.W. Declining consumption of added sugars and sugar-sweetened beverages in Australia: A challenge for obesity prevention. Am. J. Clin. Nutr. 2017, 105, 854-863. [CrossRef]

54. Barclay, A.W.; Brand-Miller, J. The Australian Paradox: A Substantial Decline in Sugars Intake over the Same Timeframe that Overweight and Obesity Have Increased. Nutrients 2011, 3, 491-504. [CrossRef] [PubMed]

55. Sichieri, R.; Yokoo, E.M.; Pereira, R.A.; Veiga, G.V. Water and sugar-sweetened beverage consumption and changes in BMI among Brazilian fourth graders after 1-year follow-up. Public Health Nutr. 2013, 16, 73-77. [CrossRef] [PubMed]

56. Rauba, J.; Tahir, A.; Milford, B.; Toll, A.; Benedict, V.; Wang, C.; Chehab, L.; Sanborn, T. Reduction of sugar-sweetened beverage consumption in elementary school students using an educational curriculum of beverage sugar content. Glob. Pediatric Health 2017, 4, 2333794X17711778. [CrossRef] [PubMed]

57. Webb, P.; Block, S. Nutrition information and formal schooling as inputs to child nutrition. Econ. Dev. Cult. Chang. 2004, 52, 801-820. [CrossRef]

58. Xu, H.; Ecker, O.; Zhang, Q.; Du, S.; Liu, A.; Li, Y.; Hu, X.; Li, T.; Guo, H.; Li, Y. The effect of comprehensive intervention for childhood obesity on dietary diversity among younger children: Evidence from a school-based randomized controlled trial in China. PLoS ONE 2020, 15, e0235951. 